\title{
Characteristics of Mechanical Properties and Microstructure of Micro Friction Stir Spot Welding of AA1100 and Brass
}

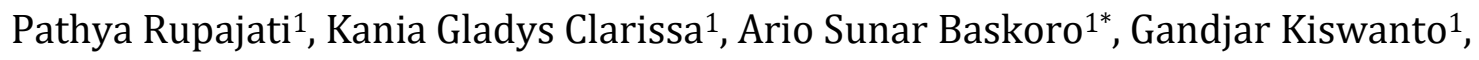 \\ Winarto $^{2}$ \\ ${ }^{1}$ Department of Mechanical Engineering, Faculty of Engineering, Universitas Indonesia, Kampus UI Depok, \\ Depok 16424, Indonesia \\ ${ }^{2}$ Department of Metallurgy and Materials Engineering, Faculty of Engineering, Universitas Indonesia, \\ Kampus UI Depok, Depok 16424, Indonesia
}

\begin{abstract}
Friction stir spot welding (FSSW) is a type of solid state welding that has been widely developed using both similar and dissimilar materials. Aluminum AA1100 (99\% Al) and brass (Cu$\mathrm{Zn}$ ) with a thickness of $0.42 \mathrm{~mm}$ are used in this welding joint. This research investigates the characteristics of the lap shear force and microstructure of micro FSSW joints on similar aluminum alloy AA1100, similar brass, and dissimilar AA1100-brass materials using a pin tool made of highspeed steel. The constant process parameters of the micro FSSW joint were plunge depth, dwell time, plunge rate, and high tool rotational speed of $0.7 \mathrm{~mm}, 6 \mathrm{~s}, 4 \mathrm{~mm} / \mathrm{min}$, and 33,000 rpm, respectively. Micro FSSW joints were carried out on similar AA1100, similar brass, and dissimilar materials whereby AA1100 was the upper sheet and brass was the lower sheet. The results of this research show that micro FSSW joints have a higher lap shear force on similar materials than dissimilar materials. The number of spots on the similar AA100 had no significant effect on the lap shear force, while with similar brass, the number of spots had a significant effect on lap shear force. The formation of a very thin intermetallic compound layer in the nugget zone occurred in the dissimilar materials. Moreover, observation results indicate that the similar AA1100 and similar brass had a lap shear force with a plug fracture type, while the type of fracture found in dissimilar materials was the interface failure mode.
\end{abstract}

Keywords: AA1100; Brass; Friction stir spot welding; Lap shear force; Microstructure

\section{Introduction}

Currently, lightweight materials such as aluminum alloys are often used in the manufacturing and automotive industries. Aluminum AA1100 is among the materials used for the manufacture of lightweight structures that are commonly used in resistance spot welding (Baskoro et al., 2017; Hakam et al., 2018), friction stir spot welding (FSSW), and conventional welding techniques such as gas tungsten arc welding. Micro FSSW is a derivative of friction stir welding, in that mFSSW uses materials with a thickness of less than $1000 \mu \mathrm{m}$, as was first discovered by TWI 1991. Micro FSSW is a solid-state joining process whereby the heat generated comes from the rotation of the tool and workpiece, and it can be used as an alternative to rivet joints. The temperature generated from this solidstate process is below the melting temperature of the base metal, so it can reduce defects 
that usually occur in conventional welding, namely porosity, distortion, residual stress, and impurity. A micro FSSW joint can be carried out on both similar and dissimilar materials. Several studies of FSSW on similar materials, including that of Lin et al. (2012), have reported that dwell time causes the bonding area to be larger, thus increasing the shear strength of an FSSW welding joint on magnesium. They also mentioned that high rotational speed and dwell time produce a finer microstructure in the stir zone to increase the shear strength of the material. Yazdi et al. (2019) observed that the use of pinless tools might increase the effective bond width area and tensile shear strength micro FSSW of $2 \mathrm{~mm}$ thickness AA6061 compared to tools with a pin. Baskoro et al. (2020) reported that dwell time does not affect the maximum temperature, but it does influence the tensile strength of the micro FSSW joint on AA1100 material the most using high-speed rotation.

An FSSW joint is used for similar materials, but several studies have successfully conducted solid-state joining using FSSW on dissimilar materials. However, welding of dissimilar material FSSW joints can lead to the formation of intermetallic compounds. Bozzi et al. (2010) observed the formation of intermetallic compound (IMC) on AA6016 and galvanized interstitial-free steel materials using tool rotational speed and penetration depth parameters. They reported that when the tool rotational speed and penetration are increased, the thickness of the IMC layer also increases. Esmaeili et al. (2011) examined friction stir welding on dissimilar materials, namely on AA1050 and brass. Li et al. (2014) studied the mechanical properties and how to reduce defects in a micro FSSW joint using a pinless tool on dissimilar AA2024 with a thickness of $1.5 \mathrm{~mm}$ using rotating speed and dwell time parameters. They reported that pinless tools reduce the formation of hook defects and increase the tensile shear load. Rao et al. (2015) investigated the effect of FSSW parameters on dissimilar materials, namely AA6022 and cast magnesium alloy. Their study stated that increasing tool rotational speed causes an increase in failure loads. In addition, the plunge depth has a significant effect on shear load. Garg and Bhattacharya (2017) observed the mechanical properties, microstructure, and fractography of similar and dissimilar FSSW joints on aluminum and copper materials using constant variables of plunge depth, dwell time, and tool rotational speed. In the dissimilar materials of AA1060 and pure copper with a thickness of $2 \mathrm{~mm}$ each, dwell time was used in the FSSW joint process parameters. Research results have stated that intermetallic compounds form intermetallic compounds (Li et al., 2019). Like the research conducted by Mubiayi and Akinlabi. (2016), they analyzed the microstructure, tensile shear, and Vickers microhardness of dissimilar materials by varying the plunge depth, rotational speed, and tool geometries. Additionally, AvetandFènoël et al. (2020) successfully combined dissimilar materials such as aluminum and brass and aluminum and copper using a zinc interlayer to undergo an FSSW joint. However, similar aluminum AA1100, similar brass, and dissimilar AA1100 and brass have not been studied in FSSW joining. It is important to study the quality characteristics of micro FSSW joints on similar and/or dissimilar materials, such as maximum strength in single spot, two spots, and three spots. Hence, the purpose of this research is to investigate the lap shear force and microstructure of micro FSSW joints with similar aluminum AA1100, dissimilar AA1100brass, and similar brass. The constant variables used were tool rotational speed, plunge rate, tilt angle and plunge depth, while the response variables studied were lap shear force and macrostructure and microstructure observed by an optical microscope.

\section{Methods}

\subsection{Materials and Experimental Set-Up}

In this study, the A1100 and brass materials used in micro FSSW both have a thickness of $0.42 \mathrm{~mm}$, as shown in Figure 2a. The chemical composition and mechanical properties of 
both materials are shown in Tables 1 and 2, respectively.

Table 1 Chemical composition of AA1100 and brass

\begin{tabular}{ccccccccc}
\hline Material & $\% \mathrm{Al}$ & $\% \mathrm{Cu}$ & $\% \mathrm{Mg}$ & $\% \mathrm{Si}$ & $\% \mathrm{Zn}$ & $\% \mathrm{Mn}$ & $\% \mathrm{Fe}$ & $\% \mathrm{~Pb}$ \\
\hline AA1100 & 99 & $0.1-0.2$ & 0.05 & $0.03-0.05$ & $0.15-0.20$ & $0.25-0.4$ & $0.05-0.1$ & - \\
Brass & - & $64-68$ & - & - & $0.1 \mathrm{Max}$ & - & 0.05 & 0.05 \\
\hline
\end{tabular}

Table 2 Mechanical properties of AA1100 and brass

\begin{tabular}{cccccccc}
\hline Material & $\begin{array}{c}\text { Ultimate } \\
\text { tensile } \\
\text { strength } \\
(\mathrm{MPa})\end{array}$ & $\begin{array}{c}\text { Yield } \\
\text { strength } \\
(\mathrm{MPa})\end{array}$ & \% Elongation & $\begin{array}{c}\text { Microhardness } \\
\text { Vickers (HV) }\end{array}$ & $\begin{array}{c}\text { Thermal } \\
\text { conductivity } \\
\text { W.m-1 } \times \mathrm{K}^{-1}\end{array}$ & $\begin{array}{c}\text { Heat } \\
\text { capacity } \\
\left(\mathrm{J} \cdot \mathrm{kg}^{-1} \times\right. \\
\left.\mathrm{K}^{-1}\right)\end{array}$ & $\begin{array}{c}\text { Melting } \\
\text { point } \\
\left({ }^{\circ} \mathrm{C}\right)\end{array}$ \\
\hline AA1100 & 115 & 105 & $15-28$ & 40 & 220 & 904 & $643-657$ \\
Brass & 365 & 140 & $40-52$ & 120 & 123 & 377 & $899-904$ \\
\hline
\end{tabular}

The FSSW machine was carried out EMCO CNC TU-3A milling machine (EMCO Group, Hallein, Austria) with an accuracy of $0.01 \mathrm{~mm}$, as shown in Figure 1. The spindle came from a Maktec turner drill machine type MT912 (Maktec by Makita Corporation, Anjo, Japan) with a die grinder specification of $6 \mathrm{~mm}$ and spindle rotation speed without load of 33,000 rpm. During micro FSSW on dissimilar materials, the AA1100 was in the form of an upper sheet, and brass was a lower sheet. The constant parameters of the mFSSW process used in this study were $6 \mathrm{~s}$ of dwell time, $0.7 \mathrm{~mm}$ plunge depth, and $4 \mathrm{~mm} / \mathrm{min}$ plunge rate, as shown in Table 3. The tool was made of high-speed steel and was prepared by turning machining. It had an inner pin diameter of $1.56 \mathrm{~mm}$, pin height of $0.61 \mathrm{~mm}$, outer pin diameter of $3.06 \mathrm{~mm}$, and pin diameter height $1.034 \mathrm{~mm}$. The diameter and height of the shoulder were $5 \mathrm{~mm}$ and $4 \mathrm{~mm}$, respectively, as shown in Figure 3.

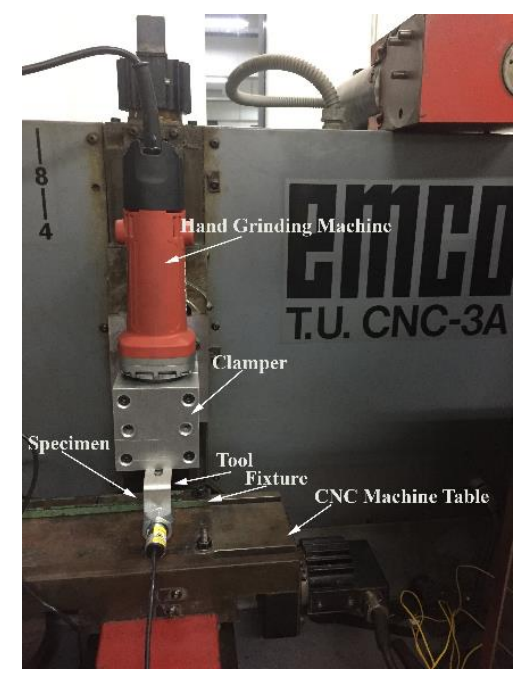

Figure 1 Experimental set-up of micro friction stir spot welding

\subsection{Mechanical Performance Test and Macro-Microstructural Characterization}

AA1100 and brass were cut into $0.42 \mathrm{~mm} \times 175 \mathrm{~mm} \times 25 \mathrm{~mm}$ samples using ISO 14273 standard, as shown in Figures $2 \mathrm{~b}$ and $2 \mathrm{c}$ for the lap shear test with two replications. The micro FSSW joint was placed in the center for all single spot specimens. For two spots, the distance between the two spots was kept at $13 \mathrm{~mm}$ for all FSSW specimens, and the distance between spots for three spots was kept as $6.5 \mathrm{~mm}$, to achieve precision for each spot (Garg and Bhattacharya, 2017). All similar and dissimilar lap shear tests joining micro FSSW were carried out using an AND Tensilon RTF 2350 universal testing machine (AND Company, Tokyo, Japan) with a capacity of $50 \mathrm{kN}$ using a cross head speed of $2 \mathrm{~mm} / \mathrm{min}$. The load and 
displacement were simultaneously recorded during the test. The cross-section of the microand macrostructure of micro FSSW joint samples was prepared by using ASTM E3 standard metallographic techniques and etched by modified Keller's reagent ( $3.0 \mathrm{~mL} \mathrm{HNO}, 2.0 \mathrm{~mL}$ $\mathrm{HCl}, 2.5 \mathrm{~mL} \mathrm{HF}$, and $90 \mathrm{~mL}$ distilled water) for $20 \mathrm{~s}$ on the AA1100 side and with a solution of $10 \mathrm{~g} \mathrm{FeCl}_{3}, 100 \mathrm{~mL} \mathrm{HCl}$, and $120 \mathrm{~mL} \mathrm{H}_{2} 0$ for $10 \mathrm{~s}$ on the brass side. All samples were then observed by Olympus BX41M-LED inverted metallurgical microscope (Olympus Corporation, Tokyo, Japan).

Table 3 Parameter process of micro FSSW for similar and dissimilar materials

\begin{tabular}{llcccc}
\hline No & \multicolumn{1}{c}{ Materials } & $\begin{array}{c}\text { Tool } \\
\text { rotational } \\
\text { speed (rpm) }\end{array}$ & Dwell time (s) & $\begin{array}{c}\text { Plunge rate } \\
(\mathrm{mm} / \mathrm{min})\end{array}$ & $\begin{array}{c}\text { Plunge depth } \\
\text { (mm) }\end{array}$ \\
\hline 1 & $\begin{array}{l}\text { AA1100-AA1100 } \\
\text { AA1100-brass }\end{array}$ & 33,000 & 6 & 4 & 0.7 \\
3 & \begin{tabular}{l} 
Brass-brass \\
\hline
\end{tabular}
\end{tabular}

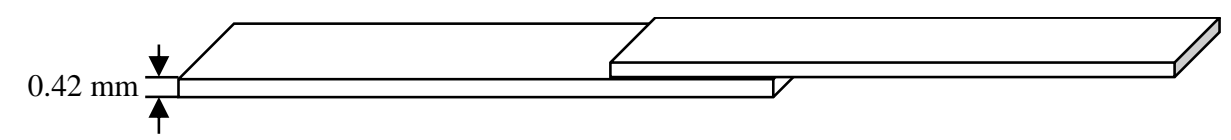

(a)

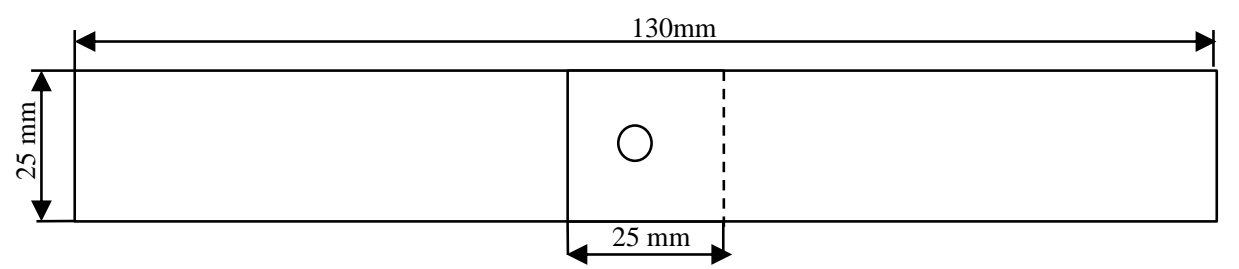

(b)

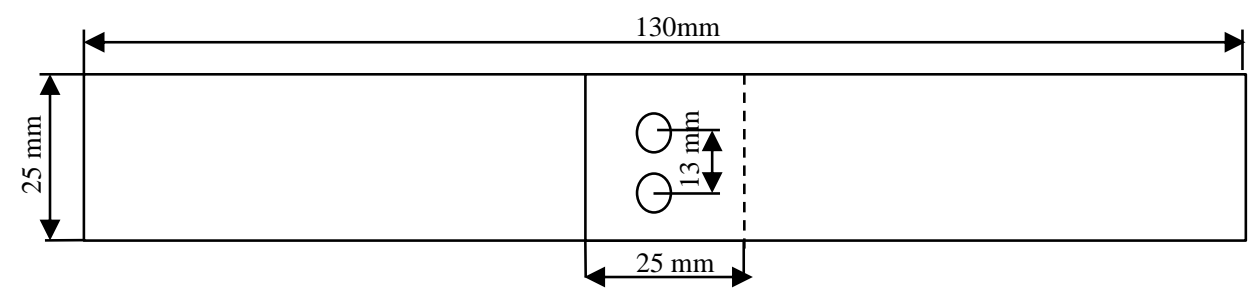

(c)

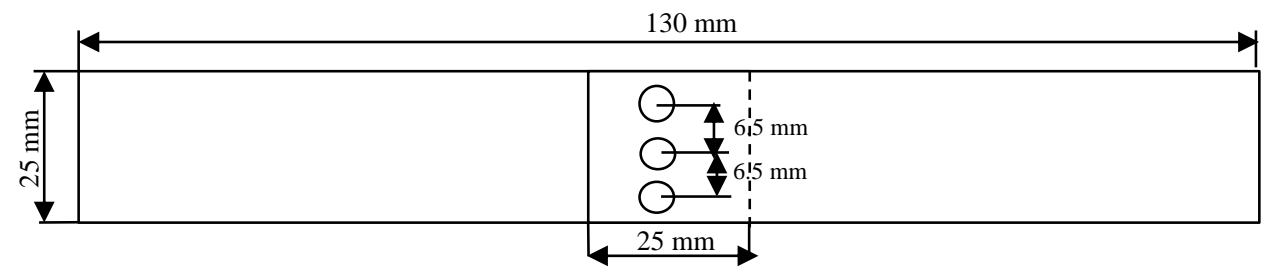

(d)

Figure 2 (a) Specimen of lap shear micro FSSW; (b) one spot; (c) two spots; and (d) three spots

Figure 3 Micro FSSW tool

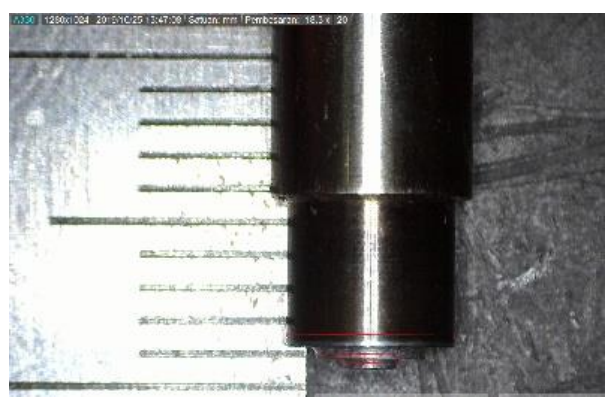




\section{Results and Discussion}

\subsection{Mechanical Properties}

The variations of lap shear force (LSF) with displacement for one-, two-, and three-spot micro FSSW joints with similar aluminum AA1100 materials using two replications are represented in Figures 4a-4d.

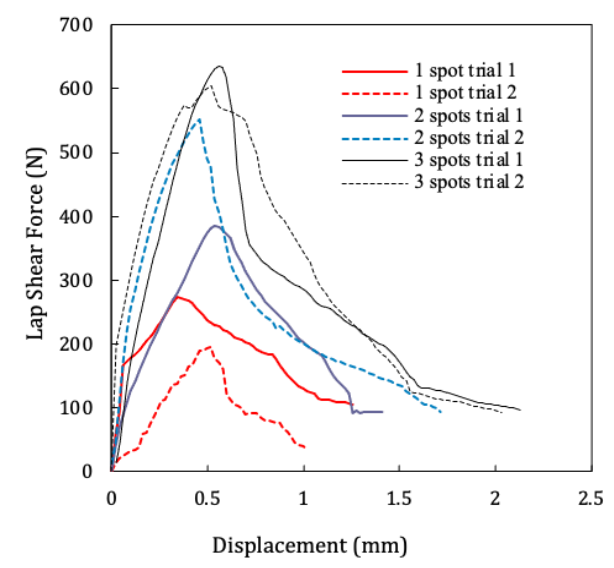

(a)

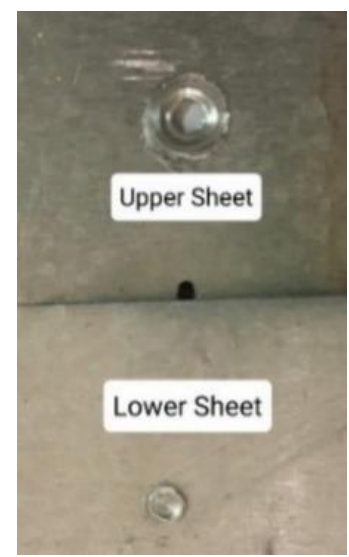

(b)

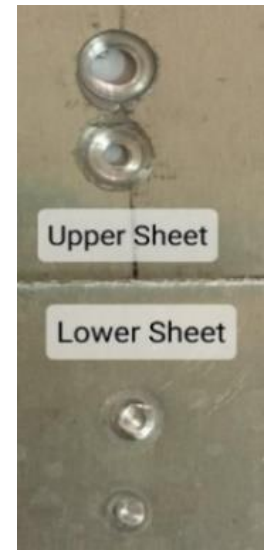

(c)

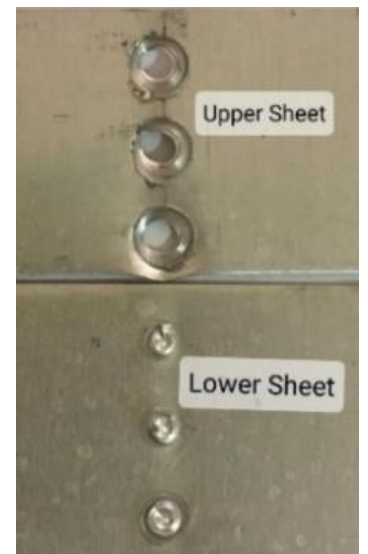

(d)

Figure 4 (a) Graph of lap shear force for similar aluminum AA1100-AA1100 micro friction stir spot welded joints for: (b) one spot; (c) two spots; and (d) three spots; failure of each spot with two replications

The experimental results show an increase-albeit insignificant- in LSF alongside an increase in the number of spots on the micro FSSW joint on similar aluminum AA1100. The maximum LSF of a single spot is $234.13 \mathrm{~N}$, which is $50.8 \%$ lower than the two-spot micro FSSW LSF of $468.82 \mathrm{~N}$. The highest maximum LSF is found with three-spot micro FSSW at $619.3 \mathrm{~N}$, which is $21.4 \%$ higher than maximum LSF in two-spot micro FSSW. Figure $4 \mathrm{a}$ shows a significant increase in single-spot and two-spot micro FSSW, but the increase is not too significant when there are additional spots at three spots, because no-uniform joints, weld width, and depth of penetration affect the joint strength of micro FSSW. The insignificance of the maximum LSF at two and three spots is due to the presence of heat in the previous spot, and when welding joints on the adjacent spot, the previously welded spots become disturbed, thereby either strengthening or weakening the weld joint. Therefore, it is necessary to calculate the distance between spots to get a significant increase in maximum LSF. In addition, the study of Garg and Bhattacharya (2017) stated that an increase in spots causes an increase in maximum LSF, although not significant. This does not mean that with more spots, the increase in maximum LSF occurs in multiples. Figures $4 \mathrm{~b}-4 \mathrm{~d}$ show the type of failure under the lap shear test specimen from the micro FSSW joint process on AA1100-AA1100, which has plug shear fail types at one spot, two spots, and three spots.

A graph of LSF with displacement for one-, two-, and three-spot micro FSSW AA1100brass joints using two replications is represented in Figure 5a. In this dissimilar joint, the AA1100 material is placed as the upper sheet, while the brass is placed as the lower sheet. The results show that the lowest maximum LSF $(121.33 \mathrm{~N})$ is in a single spot of the micro FFSW joint. The maximum LSF in the two-spot micro FFSW is $209.3 \mathrm{~N}$, having increased by $42 \%$. Meanwhile, the highest maximum LSF is $448.5 \mathrm{~N}$ in three-spot micro FSSW, increasing $53.3 \%$ compared with maximum LSF two-spot micro FFSW. Moreover, displacement in dissimilar material is lower than in similar material, since a thin layer of intermetallic compound formed in dissimilar materials. 


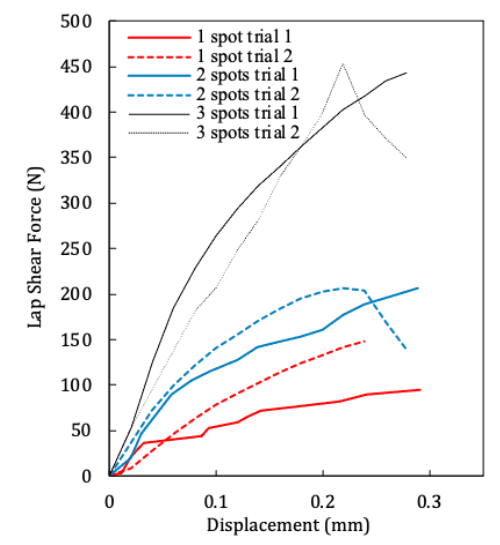

(a)

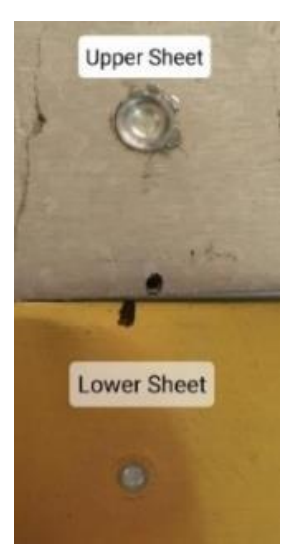

(b)

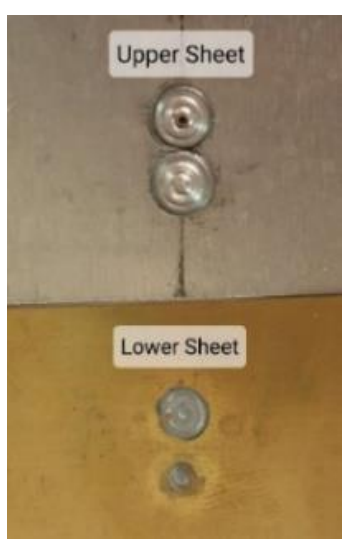

(c)

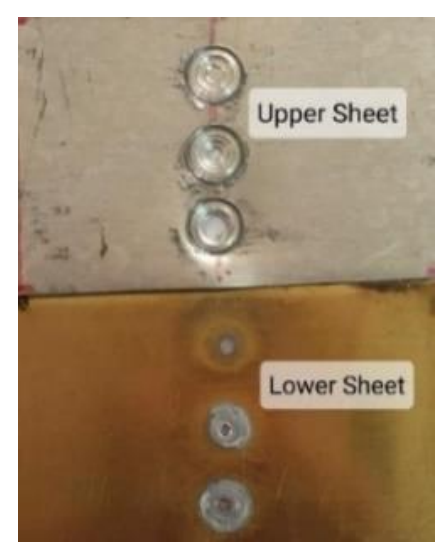

(d)

Figure 5 (a) Graph of lap shear force of dissimilar AA1100-brass micro friction stir spot welded joints for: (b) one spot; (c) two spots; and (d) three spots; failure of each spot with two replications

Figures $5 b$ and $5 c$ represent the interface failure mode of the AA1100-brass micro FSSW joints. The failure pattern in the results of dissimilar aluminum AA1100-brass micro FSSW joints in one, two, and three spots indicates an interface failure.

The graph of LSF with displacement for one-, two-, and three-spot brass-brass micro FSSW joints using two replications is represented in Figure 6a. There is a significant increase approaching 50\% in the LSF, with an increase in the number of spots in the singlespot, two-spot, and three-spot similar brass-brass micro FSSW, and the maximum LSF that occurred was $267.9 \mathrm{~N}, 564.4 \mathrm{~N}$, and 1,065 N, respectively. Overall, among the similar aluminum AA1100-AA1100, dissimilar AA1100-brass, and similar brass micro FSSW joints, the highest maximum LSF is found in the similar brass micro FSSW joints, and the lowest in dissimilar AA1100-brass micro FSSW joints. However, the displacement in the similar brass micro FSSW joints is lower than that of the similar aluminum AA1100 micro FSSW joints. The type of failure mode that occurs in a similar brass micro FSSW joint is a plug shear failure, and the same is the case with similar aluminum AA1100, because it seems a tear on the peripheral.

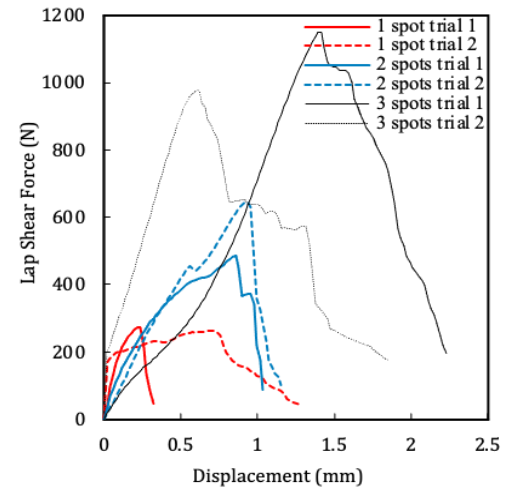

(a)

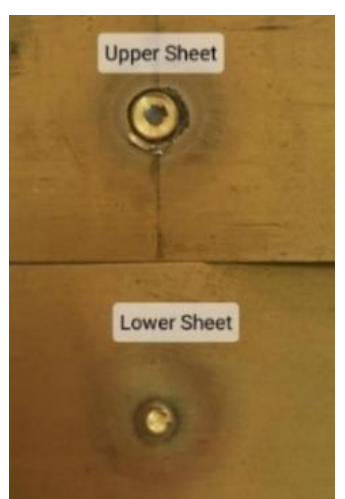

(b)

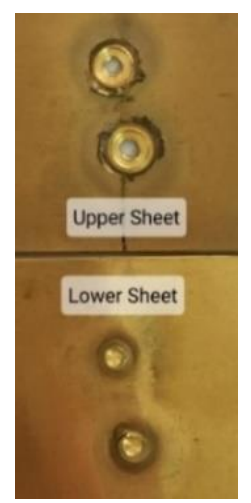

(c)

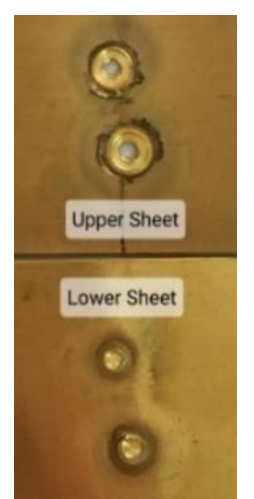

(d)

Figure 6 (a) Graph of lap shear force of similar brass-brass micro friction stir spot welded joints for: (b) one spot; (c) two spots; and (C) three spots; failure of each spot with two replications

\subsection{Macrostructure and Microstructure}

Figures 7a-7d show metallographic observations of macrostructure and microstructure of similar AA1100 micro FSSW joint cross-sections. The observation of the macrostructure shown in Figure 7a does not show the formation of flash. 


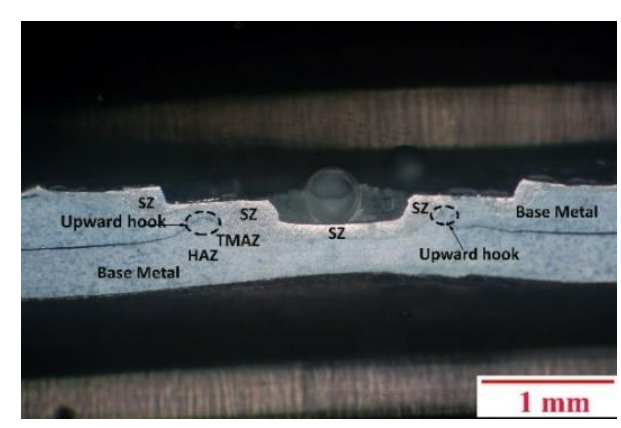

(a)

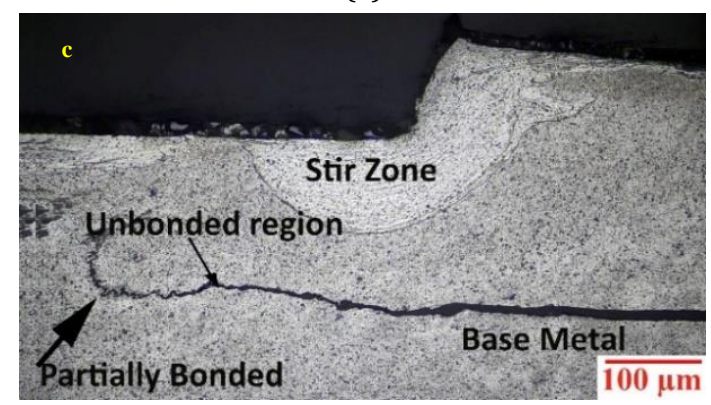

(c)

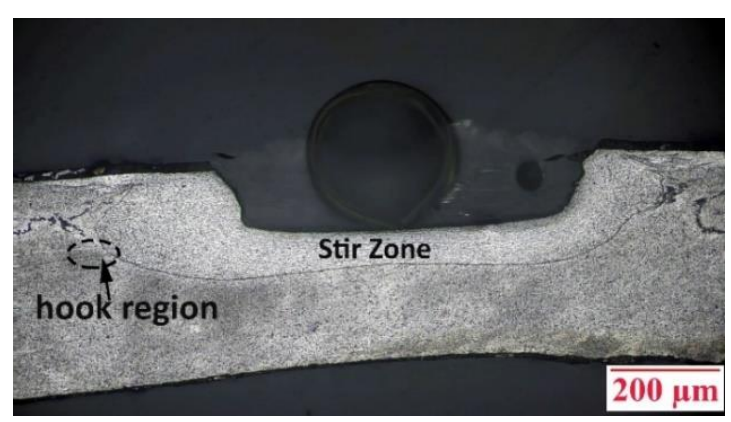

(b)

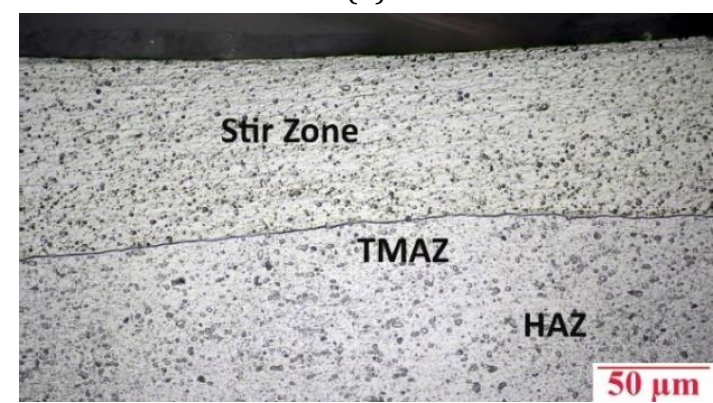

(d)

Figure 7 Optical macrostructure and microstructure of similar aluminum AA1100 micro friction stir spot welded joint

In Figures $7 \mathrm{~b}$ and $7 \mathrm{c}$, a hook is formed pointing upwards because, during the dwell time process, the rotating pin tears the material at the bottom, moving upwards towards the material on the top sheet. The formation of a hook or partial metallurgical is generally caused by tearing and breaking of the oxide layer at the interface between the two sheets of discontinuous material particles that form the hook (Badarinarayan et al., 2009). In addition, the rotational tool speed process parameter affects the formation of hooks and metallurgical bonding (Tiwan et al., 2021). The base metal (BM), HAZ, TMAZ, and stir zone in Figure $7 d$ show that the stir zone has a finer grain structure than the TMAZ and HAZ. However, for the difference in grain structure, which is finer grain in the stir zone than TMAZ, HAZ, and BM, the finer grain is due to the heat input from increasing the plunge depth (Tutar et al., 2014). The grain structure in TMAZ and HAZ is not much different. The grain structure in TMAZ is related to the rate of strain and thermal cycles, while in HAZ, the grain structure that occurs is due to the influence of heat in the SZ region (Shen et al., 2014; Garg and Bhattacharya, 2017).

Figures 8a-8d represent metallographic observations, macrostructure, and microstructure of dissimilar AA1100-brass joint cross-sections. AA1100 is placed at the upper sheet, and brass is placed at the lower sheet. Figures $8 \mathrm{~b}$ and $8 \mathrm{c}$ show that the metallurgical bonding between dissimilar materials is weak. It is shown that there has been a slight reduction in the thickness of the brass sheet, since process parameters such as tool rotational speed, dwell time, and plunge depth have not been able to penetrate the dissimilar material. However, a relatively thin intermetallic compound layer has formed accompanied by microcrack, as represented in Figure 8b. Li et al. (2019) reported that dwell time causes an increase in the thickness of the IMC resulting from FSSW joints of dissimilar materials. However, the thickness of the IMC layer tends to crack and may affect the strength of micro FSSW joints of dissimilar materials and the displacements of the joints. This was also expressed by Yeni et al. (2012) and Mubiayi and Akinlabi. (2016), who mentioned that IMC causes cracks during lap shear. Meanwhile, Zhou et al. (2019) also mentioned the effect of rotational tool speed on IMC thickness on AA1060 and copper materials and metallurgical bonding. 


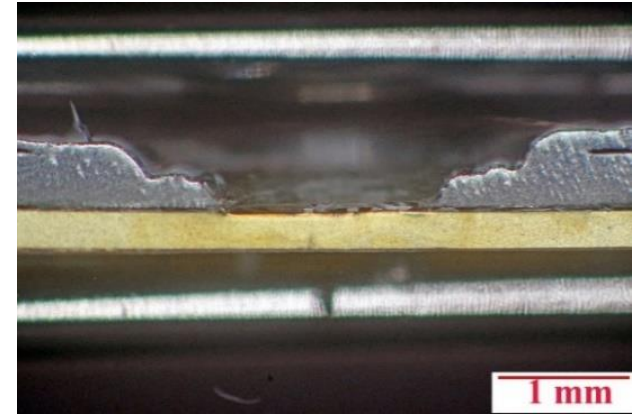

(a)

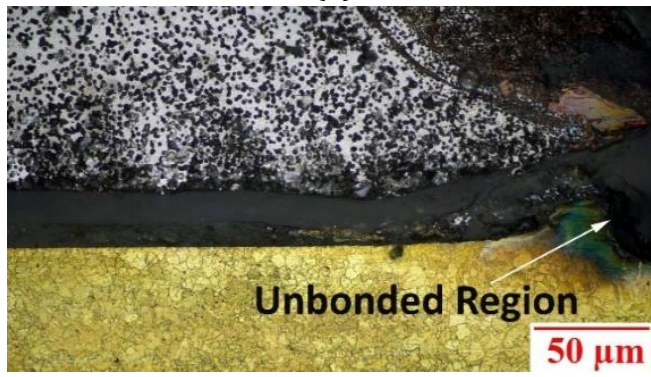

(c)

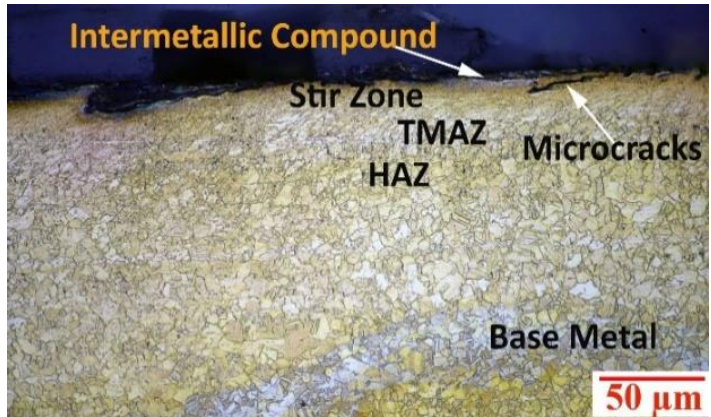

(b)

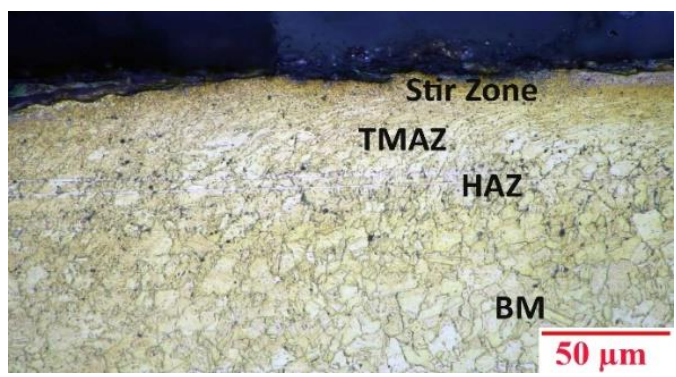

(d)

Figure 8 Optical macrostructure and microstructure of dissimilar AA1100-brass micro friction stir spot welded joint

Furthermore, Figure 8d shows that there is a difference in grain structure, where the finer grain structure is found in the stir zone, so that the difference in grain structure is due to dynamic recrystallization (Garg and Bhattacharya, 2017).

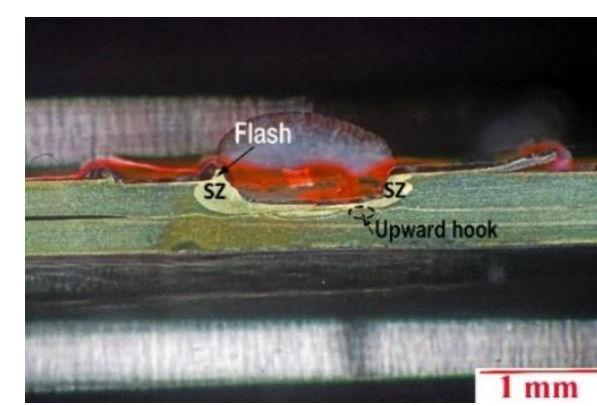

(a)

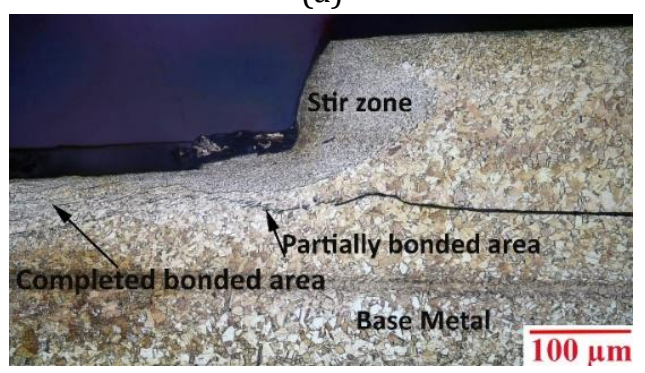

(c)

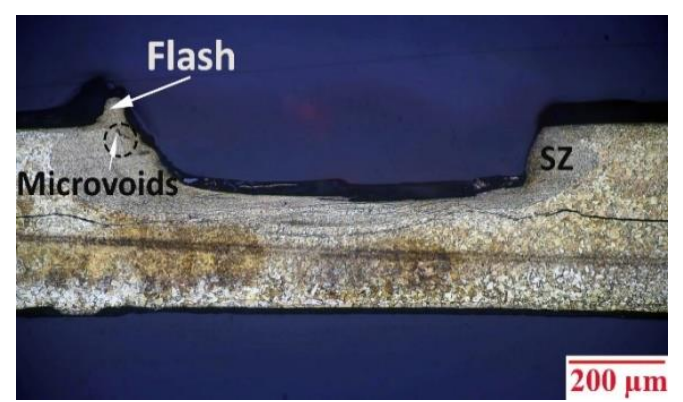

(b)

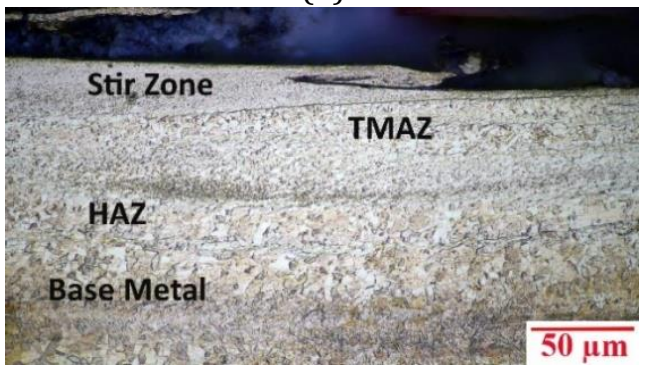

(d)

Figure 9 Optical macrostructure and microstructure of similar brass-brass micro friction stir spot welded joint

Figures 9a-9d represent metallographic observations, macrostructure, and microstructure of similar brass micro FSSW joint cross-sections. The results of the observations shown in Figure 9a show the formation of a hook on a similar brass that causes a decrease in LSF. Figure $9 \mathrm{~b}$ shows microvoid defects and a minimum flash formed due to 
friction between the tools and the workpiece during the plunging process; the material undergoes heat and is pushed upwards. Furthermore, it appears that partially bonded and unbonded regions are formed that cause failure in this joint, as shown in Figure 9c. The difference in grain size occurs in the micro FSSW joint represented in Figure 9d, where the stir zone has a finer grain structure compared to TMAZ, which is affected by dwell time and rotational speed. Research conducted by Yang et al. (2019) showed that dwell time is a significant factor in generating heat input that affects grain structure in the stir zone generated at the FSSW AZ31 magnesium Alloy.

\section{Conclusions}

This research investigated the LSF and microstructure of micro FSSW joints. Similar and dissimilar materials were used, namely aluminum AA1100-AA1100, AA1100-brass, and brass-brass. The results of this study revealed the following: (1) In similar materials, the LSF was higher than in dissimilar materials. LSF on similar brass represented a significant increase in the number of spots, but for similar AA1100 materials, the increase in LSF was insignificant; (2) Macro- and microstructure in similar and dissimilar materials indicated the formation of a hook. As a result, on the similar AA1100, there was no visible flash formation. While at the dissimilar weld joint, AA110-brass micro FSSW created weak bonding metallurgy and formed a thin intermetallic compound that tended to microcrack.

The failure mode of plug shear failure was observed on similar materials, namely both AA1100-AA1100 and brass-brass. Interface failure, whereby aluminum left traces in the nugget zone of brass sheets, was observed in the dissimilar AA1100-brass material.

\section{Acknowledgements}

This research is supported by the PUTI Q1 Research Grant from the 2020 program of the Directorate of Research and Public Services, Universitas Indonesia, with contract number NKB-4002/UN2.RST/HKP.05.00/2020.

\section{References}

Avettand-Fènoël, M.N., Nagaoka, T., Marinova, M., Taillard, R., 2020. Upon the Effect of Zn During Friction Stir Welding of Aluminum-Copper and Aluminum-Brass Systems. Journal of Manufacturing Processes, Volume 58, pp. 259-278

Badarinarayan, H., Yang, Q., Zhu, S., 2009. Effect of Tool Geometry on Static Strength of Friction Stir Spot-Welded Aluminum Alloy. International Journal of Machine Tools and Manufacture, Volume 49(2), pp. 142-148

Baskoro, A.S., Muzakki, H., Kiswanto, G., Winarto., 2017. Effects of Micro Resistance Spot Welding Parameters on the Quality of Weld Joints on Aluminum Thin Plate AA1100. International Journal of Technology, Volume 8(7), pp. 1306-1313

Baskoro, A.S., Hadisiswojo, S., Kiswanto, G., Winarto, Amat, M.A., Chen, Z.W., 2020. Influence of Welding Parameters on Macrostructural and Thermomechanical Properties in Micro Friction Stir Spot Welded Under High-Speed Tool Rotation. The International Journal of Advanced Manufacturing Technology, Volume 106(1-4), pp. 163-175

Bozzi, S., Helbert-Etter, A.L., Baudin, T., Criqui, B., Kerbiguet, J.G., 2010. Intermetallic Compounds in Al 6016/IF-steel Friction Stir Spot Welds. Materials Science and Engineering: A, Volume 527(16), pp. 4505-4509

Esmaeili, A., Givi, M.K.B., Rajani, H.R.Z., 2011. A Metallurgical and Mechanical Study on Dissimilar Friction Stir Welding of Aluminum 1050 to Brass (CuZn30). Materials Science and Engineering: A, Volume 528(22-23), pp. 7093-7102 
Garg, A., Bhattacharya, A., 2017. Similar and Dissimilar Joining of AA6061-T6 and Copper by Single and Multi-Spot Friction Stirring. Journal of Materials Processing Technology, Volume 250, pp. 330-344

ISO 14273, 2000. Specimen Dimensions and Procedure for Shear Testing Resistance Spot, Seam and Embossed Projection Welds. International Organization for Standardization, Geneva, Switzerland

Li, G., Zhou, L., Zhou, W., Song, X., Huang, Y., 2019. Influence of Dwell Time on Microstructure Evolution and Mechanical Properties of Dissimilar Friction Stir Spot Welded Aluminum-Copper Metals. Journal of Materials Research and Technology, Volume 8(3), pp. 2613-2624

Li, W., Li, J., Zhang, Z., Gao, D., Wang, W., Dong, C., 2014. Improving Mechanical Properties of Pinless Friction Stir Spot Welded Joints by Eliminating Hook Defect. Materials \& Design (1980-2015), Volume 62, pp. 247-254

Lin, Y.-C., Liu, J.-J., Lin, B.-Y., Lin, C.-M., Tsai, H.-L., 2012. Effects of Process Parameters on Strength of Mg Alloy AZ61 Friction Stir Spot Welds. Materials \& Design, Volume 35, pp. 350-357

Mubiayi, M.P., Akinlabi, E.T., 2016. Evolving Properties of Friction Stir Spot Welds Between AA1060 and Commercially Pure Copper C11000. Transactions of Nonferrous Metals Society of China, Volume 26(7), pp. 1852-1862

Muzakki, H., Baskoro, A.S., Kiswanto, G., Winarto, W., 2018. Mechanical Properties of rhe Micro Resistance Spot Welding of Aluminum Alloy to Stainless Steel with a Zinc Interlayer. International Journal of Technology, Volume 9(4), pp. 686-694

Rao, H.M., Yuan, W., Badarinarayan, H., 2015. Effect of Process Parameters on Mechanical Properties of Friction Stir Spot Welded Magnesium to Aluminum Alloys. Materials \& Design (1980-2015), Volume 66, pp. 235-245

Shen, Z., Yang, X., Yang, S., Zhang, Z., Yin, Y., 2014. Microstructure and Mechanical Properties of Friction Spot Welded 6061-T4 Aluminum Alloy. Materials \& Design (1980-2015), Volume 54, pp. 766-778

Tiwan., Ilman, M.N., Kusmono., 2021. Microstructure and Mechanical Properties of Friction Stir Spot Welded AA5052-H112 Aluminum Alloy. Heliyon, Volume 7(2), pp. 1-16

Tutar, M., Aydin, H., Yuce, C., Yavuz, N., Bayram, A., 2014. The Optimisation of Process Parameters for Friction Stir Spot-Welded AA3003-H12 Aluminum Alloy using a Taguchi Orthogonal Array. Materials and Design, Volume 63, pp. 789-797

Yang, X.W., Feng, W.Y., Li, W.Y., Dong, X., Xu, Y.X., Chu, Q., Yao, S., 2019. Microstructure and Properties of Probeless Friction Stir Spot Welding of AZ31 Magnesium Alloy Joints. Transactions of Nonferrous Metals Society of China, Volume 29(11), pp. 2300-2309

Yazdi, S.R., Beidokhti, B., Haddad-Sabzevar, M., 2019. Pinless Tool for FSSW of AA 6061-T6 Aluminum Alloy. Journal of Materials Processing Technology, Volume 267, pp. 44-51

Yeni, C.., Ozdemir, U., Sami, S., 2012. Effect of Pin Penetration Depth on the Mechanical Properties of Friction Stir Spot Welded Aluminum and Copper. Materials Testing, Volume 54(4), pp. 233-239

Zhou, L., Li, G.H., Zhang, R.X., Zhou, W.L., He, W.X., Huang, Y.X., Song, X.G., 2019. Microstructure Evolution and Mechanical Properties of Friction Stir Spot Welded Dissimilar Aluminum-Copper Joint. Journal of Alloys and Compounds, Volume 775, pp. 372-382 